\title{
Ganglioneuroma of the Internal Auditory Canal Presenting as a Vestibular Schwannoma
}

\author{
Kimon Bekelis, M.D.,, ${ }^{1}$ Duncan A. Meiklejohn, M.D., ${ }^{2}$ Symeon Missios, M.D., ${ }^{1}$ \\ Brent Harris, M.D., ${ }^{3}$ James E. Saunders, M.D., ${ }^{2}$ and Kadir Erkmen, M.D. ${ }^{1}$
}

In most series, $90 \%$ of cerebellopontine angle tumors are vestibular schwannomas. Meningiomas and epidermoid tumors follow with decreased frequency. Ganglioneuroma is a benign tumor usually found in the retroperitoneum and posterior mediastinum. We report a case of a 21-year-old man with gradual sensorineural hearing loss and a minimally enhancing lesion of the internal auditory canal, which was excised through a middle fossa approach and found histologically to be a ganglioneuroma. Like vestibular schwannomas, these lesions are benign in nature and may be managed in a similar fashion, although the possibility of malignant transformation may support surgical resection over conservative management or radiosurgery. Ganglioneuromas should be considered in patients with atypical radiographic findings for vestibular schwannomas.

KEYWORDS: Ganglioneuroma, vestibular schwannoma, internal auditory canal, cerebellopontine angle

Most of the lesions encountered in the cerebellopontine angle are schwannomas and meningiomas. A small proportion of the lesions can represent widely varied pathologies such as epidermoid tumors, lipomas, lymphomas, vascular malformations, gliomas, cholesterol granulomas, choroid plexus tumors, neuroblastomas, and arachnoid cysts. Ganglioneuroma is a slowgrowing benign tumor derived from cells of neural crest lineage. It most frequently arises from cells found in the sympathetic ganglia and the adrenal medulla and usually occurs in patients between the ages of 10 and 30, with a mean age of 7 years. ${ }^{1-3}$ Histologically, these tumors are composed of mature autonomic ganglion cells, immature ganglion cells, satellite cells, Schwann cells, and unmyelinated and myelinated axons in a fibrous stroma. ${ }^{1,3}$ Common locations for these tumors include the posterior mediastinum and retroperitoneum, though they are infrequently found in the head and neck region. ${ }^{4-10}$ Ganglioneuromas have also been reported in the cerebellopontine angle. ${ }^{11}$ In the current report, we present a case of a ganglioneuroma in a young patient presenting as a slowly growing mass within the internal auditory canal (IAC) with associated hearing loss and normal facial nerve function, mimicking a vestibular schwannoma. We compare our results and findings with a previous report of a cerebellopontine angle ganglioneuroma in an older adult. ${ }^{11}$

\section{CASE REPORT}

\section{History and Examination}

A 21-year-old right-handed man presented with a history of left-sided sensorineural hearing loss first noted
Sections of ${ }^{1}$ Neurosurgery, ${ }^{2}$ Ear Nose and Throat Surgery, and ${ }^{3}$ Pathology, Dartmouth-Hitchcock Medical Center, Lebanon, New Hampshire.

Address for correspondence and reprint requests: Kadir Erkmen, M.D., Section of Neurosurgery, Dartmouth-Hitchcock Medical Center, One Medical Center Drive, Lebanon, NH 03756 (e-mail: Kadir.Erkmen@hitchcock.org).
Skull Base Rep 2011;1:89-94. Copyright (C) 2011 by Thieme Medical Publishers, Inc., 333 Seventh Avenue, New York, NY 10001, USA. Tel: +1(212) 584-4662.

Received: December 14, 2010. Accepted: December 28, 2010. Published online: April 11, 2011.

DOI: http://dx.doi.org/10.1055/s-0031-1276722.

ISSN 2157-6971. 
at age 13 . He declined evaluation for his hearing loss until age 21 , when more rapid deterioration of his hearing and mild balance difficulties led to brain magnetic resonance imaging (MRI). Audiometric assessment indicated a moderate left-sided sensorineural deficit between 1500 and $8000 \mathrm{~Hz}$.

MRI images of the brain were obtained before and after administration of gadolinium contrast. A poorly defined 7- to 8-mm mass was evident within the IAC on the left side. The mass was hypointense on T1 and had high, heterogenous T2 signal. There was no enhancement on early postcontrast images, and there was only mild enhancement with delayed images (Fig. 1). No other abnormalities were visualized. Specifically, there was no edema and no associated mass effect, and there was no evidence of erosion of the surrounding bone.

\section{Intervention}

The patient elected to undergo surgical resection of the tumor. Neuromonitoring was performed with auditory brain stem responses (ABRs), direct acoustic nerve monitoring, and left facial nerve electromyogram. A left preauricular middle fossa approach was used. There was a $50 \%$ decline in the ABRs on the left side during drilling of the IAC, which spontaneously returned to baseline. The tumor was firm in consistency and noted to arise between the superior and inferior vestibular nerves, with adhesions to the cochlear nerve and facial nerve.
A
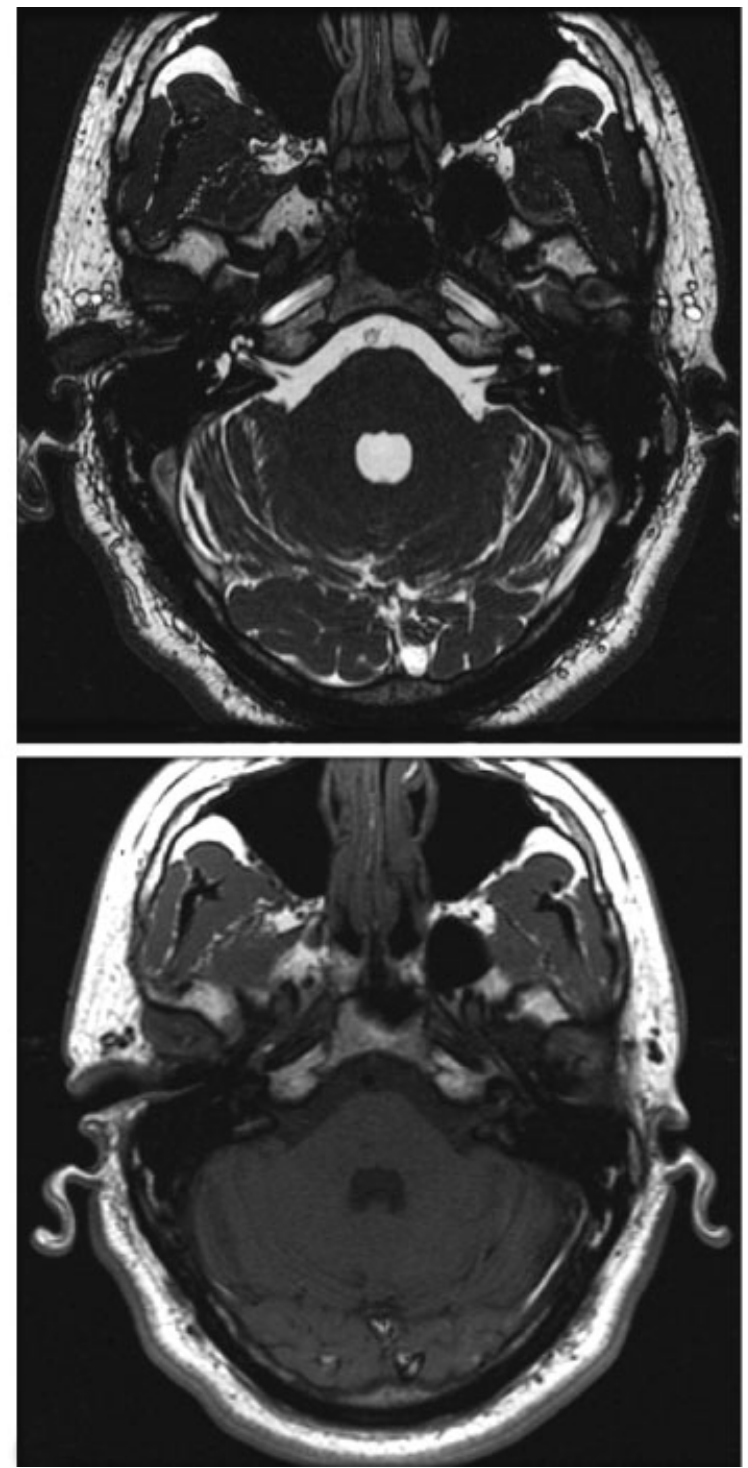

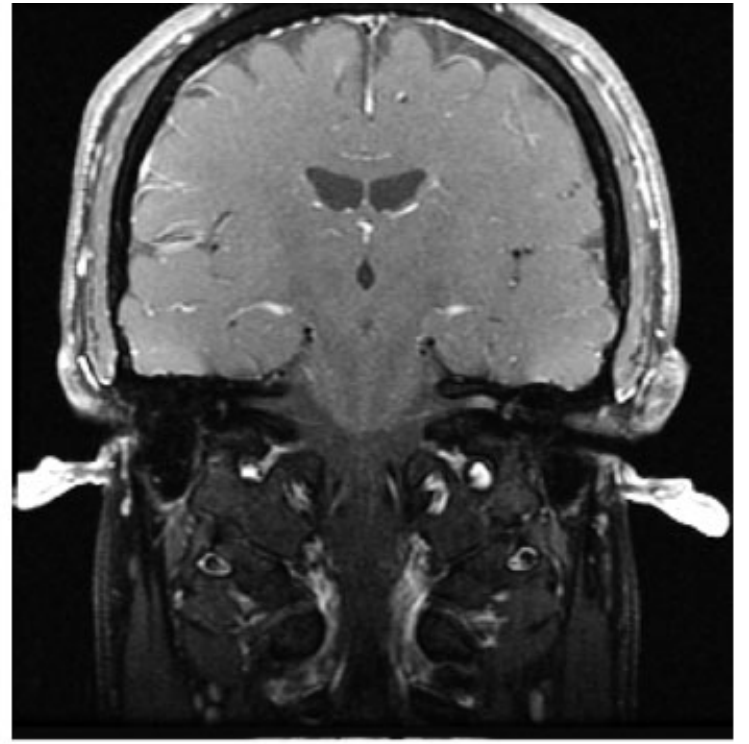

C

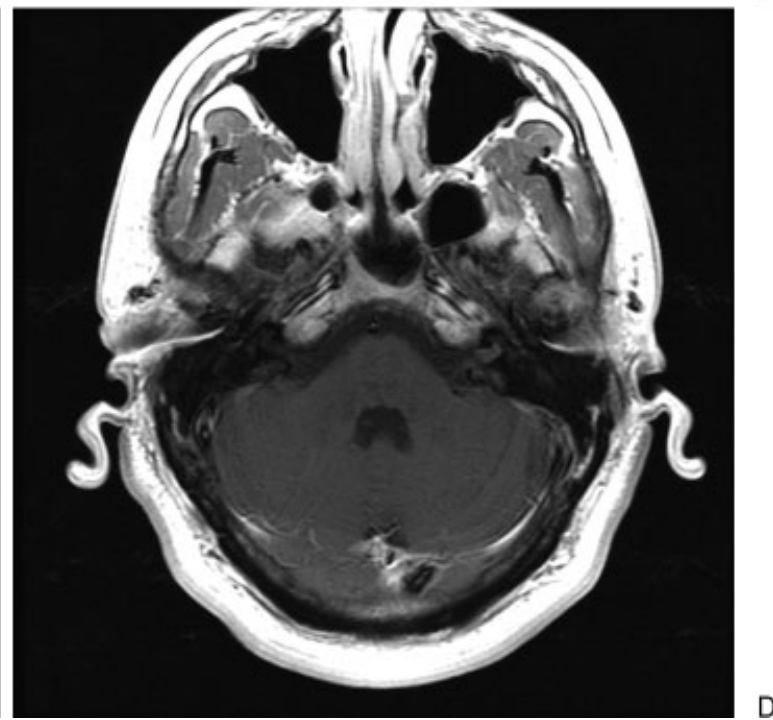

Figure 1 Preoperative magnetic resonance imaging of the brain. (A) Axial FIESTA image demonstrating the ganglioneuroma of the left internal auditory canal (IAC). (B) Axial image demonstrating low T1 intensity of the ganglioneuroma. (C) Coronal image demonstrating moderate uptake of gadolinium contrast of the ganglioneuroma in the left IAC. (D) Axial image demonstrating moderate uptake of gadolinium contrast of the ganglioneuroma in the left IAC. 

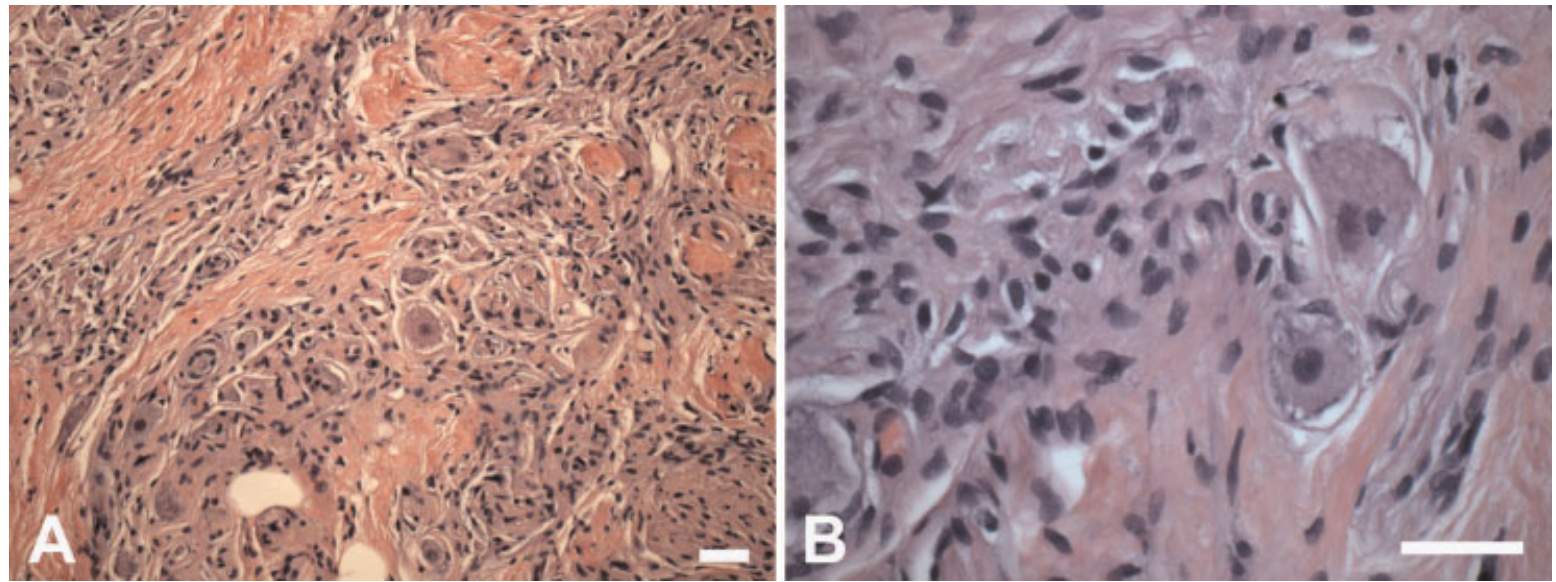

Figure 2 (A) Ganglioneuroma histopathology displays scattered ganglion cells amidst dense bundles of fibers ensheathed by Schwann cells. (B) Higher magnification highlights ganglion cells with vacuolated cytoplasm and surrounding satellite cells. Hematoxylin and eosin, measurement bars $=20 \mu \mathrm{m}$.

The tumor was removed from the involved nerves using sharp dissection, and the IAC was covered with a fat graft that was harvested from a separate abdominal incision. Inspection of the field revealed gross total resection of the tumor with intact facial and cochlear nerves. Stimulation potentials of the left facial nerve and $\mathrm{ABR}$ sere unchanged at the completion of tumor resection.

During the immediate postoperative period, the patient had mild left facial weakness with a HouseBrackmann score of 2. The MRI revealed expected postoperative findings and no evidence of residual tumor. His postoperative course remained uneventful. His facial function returned to normal, and at 3 months postoperatively, facial function was full and symmetrical. Audiometry performed 2 moths postoperatively was unchanged from the preoperative assessment.

\section{Histopathology}

The tumor specimen measured $6 \times 7 \times 6 \mathrm{~mm}$ and grossly had a homogeneous tan appearance on cut bisection without obvious nerve attachment. On microscopic examination, the tumor displayed multiple bundles of nerves in haphazard arrays within fibrous tissue (Fig. 2). Schwann cells were found within the nerve bundles, but minimal myelin ensheathment was seen. Scattered amidst the axonal collections were gangliontype cells either individually or in small collections. These ganglion cells were well differentiated, showing enlarged nuclei with prominent nucleoli and abundant cytoplasm with variable amounts of Nissl substance. Some ganglion cells had mildly vacuolated cytoplasm, though this could be a processing artifact. No cytoplasmic inclusions were seen. Satellite cell nuclei were found around many of the ganglion cells.

The tumor was fixed in $10 \%$ formalin, paraffin embedded, and cut into 5- $\mu \mathrm{m}$-thick sections. The tissue sections were stained with hematoxylin and eosin (Fig. 3A). Immunohistochemical staining with the streptavidin-biotin peroxidase complex method was performed with the following antibodies: glial fibrillary acidic protein (GFAP, 1:8000; BioGenex, San Ramon, CA), neurofilament 2F11 (1:100; Dako, Carpinteria, CA), S100 (1:200; Sigma-Aldrich, St. Louis, MO).

Immunohistochemical analysis was performed to highlight glial and neuronal elements. Neurofilament marker 2F11 immunostained thin axonal processes in bundles and ganglion cell soma (Fig. 3B). S100 highlighted Schwann cells and perineuronal satellite cells (Fig. 3C). It also weakly stained many of the ganglion cells. Glial marker GFAP failed to stain any cells within the tumor (Fig. 3D).

\section{DISCUSSION}

Neural crest cells give rise to ganglion cells of the sympathetic nervous system (SNS) and parasympathetic nervous system. These ganglion cells of the SNS are the source lineage for ganglioneuromas. Tumorigenesis can occur through primary maturation of ganglion cells to tumor or by differentiation of other SNS tumors such as neuroblastoma or ganglioneuroblastoma through necrosis or maturation of the neuroblasts during the early stages of tumor development. ${ }^{11,12}$ Unlike these more aggressive tumors, ganglioneuromas are benign, although malignant differentiation can occur. In addition, they usually do not secrete catecholamines at high enough levels to be symptomatic. ${ }^{1,7,13}$ The patient in this report did not have clinical signs of catecholamine release, although urine catecholamines were not measured. Intracranial presentations of ganglioglioma are extremely rare. A previous report demonstrated such a tumor in the cerebellopontine angle. ${ }^{11}$ The only other intracranial location of a ganglioneuroma was reported to be associated with the trigeminal nerve. ${ }^{4}$ 

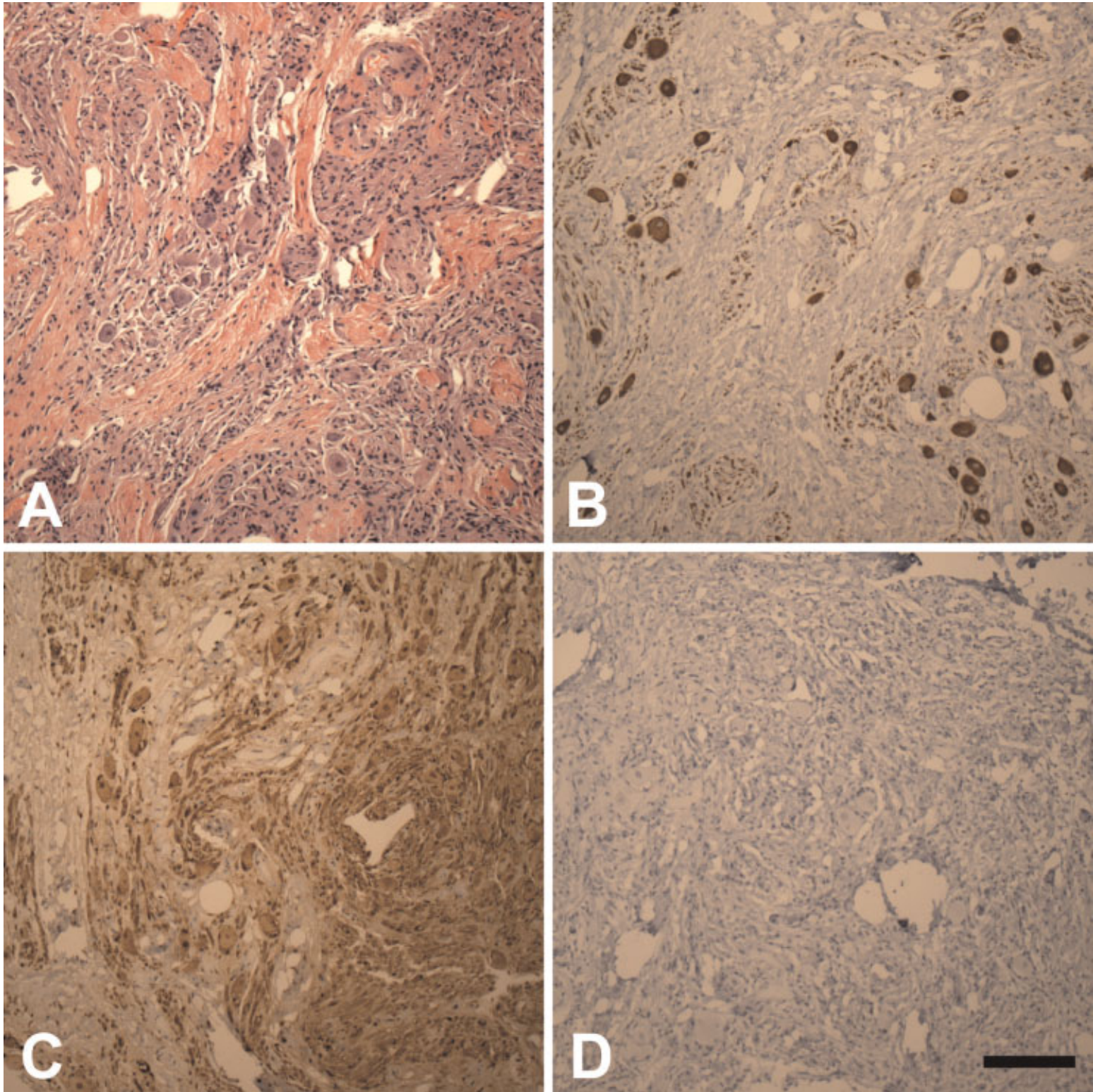

Figure 3 Immunohistochemical profile of ganglioneuroma highlights neurofilament in ganglion cell soma and bundles of processes (B), ensheathing Schwann cells positive for S100 (C), and no glial fibrillary acidic protein immunoreactivity (D). (A) Hematoxylin and eosin stain, measurement bar $=100 \mu \mathrm{m}$.

These tumors usually come to clinical attention either incidentally or due to local mass effect on nerves. ${ }^{8}$ Our patient's presentation was suggestive of mass effect on the vestibulocochlear nerve, with hearing loss as the primary symptom. This presentation pattern is consistent with a previous report of an IAC ganglioneuroma in a 50 -year-old patient. ${ }^{11}$ However, the patient in this report had progressive hearing loss since childhood, suggesting a possible pediatric origin of his ganglioneuroma. This underscores the extremely slow-growing nature of these tumors and supports the varied etiology of ganglioneuromas. It could be hypothesized that intracranial ganglioneuromas occurring in younger patients may arise from ectopic sympathetic nervous tissue such as a hamartomatous lesion, whereas those observed in older patients might result from somatic mutation of SNS-derived tumors. However, the rarity of these lesions would make this hypothesis difficult to assess. In the IAC, ganglioneuromas could arise from autonomic tissue in the nervous intermedius nerve.

On computed tomographic imaging, ganglioneuromas are typically low-attenuation, homogenous masses that may show fine calcifications. They show low to moderate enhancement that can be either homogenous or heterogeneous. On MRI, ganglioneuromas typically display low T1 and heterogeneous, high T2 signal. ${ }^{13-15}$ Administration of gadolinium results in variable enhancement, with delayed images potentially showing increased enhancement over time. ${ }^{13-15}$ This pattern of enhancement should draw the clinician's 
attention to the possibility of a ganglioneuroma. The MRI findings in this patient were consistent with the previous literature of ganglioneuromas of the IAC. ${ }^{11}$ The tumor displayed a very low level of enhancement on postgadolinium images.

Treatment for symptomatic extracranial ganglioneuromas consists of complete surgical excision, with radiological surveillance for local recurrence. ${ }^{1,7,8,13,16}$ Watchful waiting, even in asymptomatic cases, is often avoided in extracranial ganglioneuromas due to reports of malignant transformation to neuroblastoma. ${ }^{7,8}$ Due to this potential risk for malignant transformation of the lesion, radiotherapy is also not recommended. ${ }^{16}$ With complete resection, prognosis is usually excellent. ${ }^{17}$

A middle fossa approach was utilized due to the small tumor size and goal of preservation of hearing. Similar to the prior report, our patient has had no deterioration in auditory function postoperatively, ${ }^{11}$ which is common for vestibular schwannomas resected through a middle fossa approach. ${ }^{18-20} \mathrm{~A}$ stereotactic radiosurgical approach for ganglioneuroma is possible; however, this has not been reported. The potential risk for malignant transformation would make this option less favorable.

Glioneural hamartomas of the acoustic nerve, a similarly slow-growing benign lesion, have also been reported. ${ }^{21-23}$ These tumors seem to demonstrate greater infiltration of the facial and cochlear nerve complex, requiring partial resection or sacrifice of the acoustic nerve in two of the four reported cases. ${ }^{21-23} \mathrm{In}$ our case, the tumor was noninfiltrative, and complete resection was possible with good postoperative results. There was no tumor recurrence in follow-up 1 year postoperatively.

\section{CONCLUSION}

Ganglioneuroma is a benign tumor of the sympathetic peripheral nervous system. In the present report, we describe an extremely rare presentation of a ganglioneuroma as a tumor of the IAC, with definitive surgical treatment and good recovery to this date. Poor MRI contrast uptake may be an aid to preoperative diagnosis. Preoperative diagnosis is worthwhile, because watchful waiting and radiosurgical intervention may not be optimal due to the risk of malignant transformation. Longterm prognosis for patients with ganglioneuroma of the IAC is likely excellent with complete surgical resection.

\section{REFERENCES}

1. Geoerger B, Hero B, Harms D, Grebe J, Scheidhauer K, Berthold F. Metabolic activity and clinical features of primary ganglioneuromas. Cancer 2001;91:1905-1913
2. Scheithauer BW, Woodruff JM, Erlandson RA. Ganglioneuroma. In: Tumors of the Peripheral Nervous System. Bethesda, MD: Armed Forces Institute of Pathology; 1999:259

3. Slattery WH III, Brackmann DE, Hitselberger W. Middle fossa approach for hearing preservation with acoustic neuromas. Am J Otol 1997;18:596-601

4. Abe T, Asano T, Manabe T, Matsuura H, Furuta T, Taguchi K. Trigeminal ganglioneuroma. Brain Tumor Pathol 1999; $16: 49-53$

5. Brouwers FM, Eisenhofer G, Lenders JW, Pacak K. Emergencies caused by pheochromocytoma, neuroblastoma, or ganglioneuroma. Endocrinol Metab Clin North Am 2006; 35:699-724; viii

6. Estefano J, Algaba J, Gorostiaga F, Urruticoechea A, Hernández JM. Ganglioneuroma of the middle ear. Apropos of a case. An Otorrinolaringol Ibero Am 1992;19:5-12

7. Kaufman MR, Rhee JS, Fliegelman LJ, Costantino PD. Ganglioneuroma of the parapharyngeal space in a pediatric patient. Otolaryngol Head Neck Surg 2001;124:702704

8. Lonergan GJ, Schwab CM, Suarez ES, Carlson CL. Neuroblastoma, ganglioneuroblastoma, and ganglioneuroma: radiologic-pathologic correlation. Radiographics 2002;22: 911-934

9. Ozluoglu LN, Yilmaz I, Cagici CA, Bal N, Erdogan B. Ganglioneuroma of the internal auditory canal: a case report. Audiol Neurootol 2007;12:160-164

10. Radin R, David CL, Goldfarb H, Francis IR. Adrenal and extra-adrenal retroperitoneal ganglioneuroma: imaging findings in 13 adults. Radiology 1997;202:703-707

11. Palmer CA, Townsend JJ, Harnsberger HR, Parkin JL, Apfelbaum RI. Cerebellopontine angle glioneuronal hamartoma. Surg Neurol 1996;45:467-469

12. Ambros IM, Zellner A, Roald B, et al. Role of ploidy, chromosome $1 \mathrm{p}$, and Schwann cells in the maturation of neuroblastoma. N Engl J Med 1996;334:15051511

13. Miura K, Mineta H, Yokota N, Tsutsui Y. Olfactory neuroblastoma with epithelial and endocrine differentiation transformed into ganglioneuroma after chemoradiotherapy. Pathol Int 2001;51:942-947

14. Ichikawa $\mathrm{T}$, Ohtomo $\mathrm{K}$, Araki $\mathrm{T}$, et al. Ganglioneuroma: computed tomography and magnetic resonance features. $\mathrm{Br} \mathrm{J}$ Radiol 1996;69:114-121

15. Rha SE, Byun JY, Jung SE, Chun HJ, Lee HG, Lee JM. Neurogenic tumors in the abdomen: tumor types and imaging characteristics. Radiographics 2003;23:29-43

16. Califano L, Zupi A, Mangone GM, Long F. Cervical ganglioneuroma: report of a case. Otolaryngol Head Neck Surg 2001;124:115-116

17. Leonardis M, Sperb D, Alster C, Campisi C, Herter NT. Ganglioneuroma of the neck, masquerading as a goiter. Eur J Surg Oncol 2003;29:929-930

18. Hillman T, Chen DA, Arriaga MA, Quigley M. Facial nerve function and hearing preservation acoustic tumor surgery: does the approach matter? Otolaryngol Head Neck Surg 2010;142:115-119

19. Irving RM, Jackler RK, Pitts LH. Hearing preservation in patients undergoing vestibular schwannoma surgery: comparison of middle fossa and retrosigmoid approaches. J Neurosurg 1998;88:840-845 
20. Stárek I, Mihál V, Novák Z, Pospísilová D, Vomácka J, Vokurka J. Pediatric tumors of the parapharyngeal space. Three case reports and a literature review. Int J Pediatr Otorhinolaryngol 2004;68:601-606

21. Carvalho GA, Matthies C, Osorio E, Samii M. Hamartomas of the internal auditory canal: report of two cases. Neurosurgery 2003;52:944-948; discussion 948-949
22. Gonul E, Yetiser S, Tasar M, Ongoru O. Glioneural hamartoma of the VIIIth nerve. J Laryngol Otol 2006;120: 70-73

23. Pucci A, Pucci E, Santini F, et al. A ganglioneuroma with features of a thyroid nodule: intense pain on fine needle biopsy as a diagnostic clue. Thyroid 2009;19:201-204 